\title{
Menguji keberadaan structural breaks pada transmisi kebijakan moneter di Indonesia
}

\author{
Imronjana Syapriatama1, ${ }^{*}$, Intan Kusuma Pratiwi ${ }^{2}$ \\ Universitas Islam Negeri Mataram, Indonesia ${ }^{1,2}$ \\ Corresponding e-mail: imron.js@gmail.com*
}

\begin{abstract}
submitted: $\quad$ Purpose - This paper investigates the presence of structural breaks in order Sep-09, 2019 to determine the regime shift in case of Indonesia economy.

accepted: $\quad$ Research method - We use the Bai-Perron (2003) to test the breaks within Nov-13,2019 the period of January 2014 - December 2018 and Structural Vector Autoregression (VAR) to generate the model constructed to analyze the published: monetary transmission mechanism.

Dec-02, 2019 Result - The result shows that there are four significant structural breaks while SVAR shows the negative relationship between SBIS and the Output and a negative relationship between PUAS and Inflation.
\end{abstract}

Keywords: monetary transmission, structural breaks, structural VAR 


\section{PENDAHULUAN}

Penelitian-penelitian dengan data runtun waktu umumnya dimulai dengan prosedut uji stasioneritas untuk menentukan keberadaan unit root. Uji standar yang biasa digunakan adalah uji Augmented Dickey-Fuller ${ }^{1}$. Namun, keraguan mulai muncul ketika sampel penelitian diyakini mengandung event ekonomi yang berdampak pada pergeseran regime ${ }^{2}$. Dengan mengasumsikan adanya pergeseran regime, maka diperlukan uji unit root yang mempertimbangkan adanya break point dalam suatu runtun waktu. Salah satu metode yang menguji adanya unit root adalah uji Bai-Perron. Bai dan Perron ${ }^{3}$ mengembangkan sebuah metodologi untuk menemukan Structural Breaks dalam runtun waktu dan menguji signifikansinya secara statistik ${ }^{4}$. Structural Breaks yang dimaksud merupakan pergeseran perilaku pada suatu runtun waktu akibat adanya perubahan permanen dalam strukur ekonomi. Secara alternatif, perubahan perilaku dapat juga bersifat temporer, seperti kasus-kasus ekonomi yang mengalamai depresi, hiperinflasi, atau krisis keuangan.

Pengujian Structural Breaks dalam penelitian ini dilakukan pada proses transmisi kebijakan moneter bebas bunga. Taylor ${ }^{5}$ menyebutkan bahwa transmisi kebijakan moneter adalah proses yang menggambarkan bagaimana kebijakan moneter yang ditransmisikan dapat merubah tingkat pertumbuhan dan inflasi. Mekanisme transmisi kebijakan moneter dapat ditransmisikan melalui jalur suku bunga, jalur kredit, harga aset, dan jalur nilai tukar6. Alat utama bank sentral untuk mengatur ekonomi adalah suku bunga. Namun, hal ini dapat menjadi masalah pada Negara dengan populasi mayoritas muslim. Selain itu, beberapa ilmuwan juga berpendapat bahwa penerapan suku bunga berbanding lurus dengan kebangkrutan perusahaan ${ }^{7}$ serta tidak mampu mengontrol sistem ekonomi ${ }^{8}$. Menghadapai hal ini, Bank Indonesia menerbitkan surat berharga yang disebut Sertifikat Bank Indonesia Syariah (SBIS) yang diadaptasi dari Sertifikat Bank Indonesia (instrumen dengan suku bunga) sebagai solusi alternatif.

Penelitian ini bertujuan untuk menguji keberadaan pergerseran regime yang ditunjukkan dengan adanya Structural Breaks dalam data runtun waktu pada indikator makroekonomi yang digunakan sebagai variabel dalam mekanisme transmisi kebijakan moneter bebas bunga di Indonesia. Bagian kedua penelitian membahas Data dan Metodologi, bagian ketiga membahas Hasil, dan Kesimpulan ditampilkan pada bagian terakhir.

\footnotetext{
${ }^{1}$ Lihat Augmented Dickey-Fuller (1979)

${ }^{2}$ Lohat Lee \& Chang (2005)

${ }^{3}$ Bai perron (1998, 2003a dan 2003b) mengembangkan sebuah uji untuk menemukan structural breaks

4 Lihat Antoshin, Berg, \& Souto (2008)

${ }^{5}$ Taylor (1995) menjelaskan mengenai beberapa jalur dalam transmisi kebijakan moneter

${ }^{6}$ Lihat Mishkin (1995) dalam symposium kebijakan moneter

7 Lihat Greenwald \& Stiglitz (2003) dan Campbell \& Choudhury (2005)

8 Lihat Uddin \& Halim (2015)
} 


\section{METODE PENELITIAN}

Untuk mencapai tujuan penelitian, digunakan mekanisme transmisi moneter jalur bebas bunga dengan metode Structural Vector Autoregression (SVAR). Penelitian menggunakan data periode Januari 2014 - Desember 2018. Data penelitian yang digunakan sebagai variabel endogen adalah Industrial Production Index (IPI), Consumer Price Index (CPI), tingkat bonus Sertifikat Bank Indonesia Syariah (SBIS), dan tingkat Pasar Uang Antarbank Syariah (PUAS). Data-data tersebut diperoleh dari Bank Indonesia (BI). Mengedaptasi model penelitian Jain-Chandra \& Unsal $^{9}$, digunakan model SVAR untuk mengestimasi hubungan antara kebijakan moneter SBIS terhadap IPI dan CPI yang ditunjukkan pada persamaan (1).

$$
\mathrm{Yt}=\mathrm{a}_{0}+\sum_{\mathrm{i}=1}^{\mathrm{n}} \mathrm{a}_{\mathrm{i}} \mathrm{Y}_{\mathrm{t}-1}+\mathrm{e}_{\mathrm{t}} . .(1)
$$

Y adalah vektor variabel endogen (SBIS, PUAS, IPI, CPI). Untuk menghindari data yang mencolok, variabel ditransformasi menjadi bentuk logaritma natural kecuali SBIS dan PUAS karena telah berbentuk persentase. Penggunaan SVAR bertujuan untuk mendukung penelitian, SVAR berbentuk non-orthogonal, sehingga diperlukan teori ekonomi dalam proses transmisi antar variabel. Penereapan model tersebut memudahkan fokus penelitian pada hubungan struktural antara kebijakan bebas bunga, intermediate target, dan makroekonomi target. Persamaan matrix (2) menggambarkan SVAR yang digunakan dalam penelitian. Urutan yang digunakan didasarakan pada penelitian sebelumnya. Output diikuti oleh inflasi sedangkan kebijakan moneter diasumsikan contemporaneously lebih eksogen daripada pasar uang bank syariah karena pasar uang bereaksi setelah kebijakan moneter ${ }^{10}$.

$$
\mathrm{Yt}=\mathrm{a}_{0}+\sum_{\mathrm{i}=1}^{\mathrm{n}} \mathrm{a}_{\mathrm{i}} \mathrm{Y}_{\mathrm{t}-1}+\mathrm{bZ}_{\mathrm{t}}+\mathrm{e}_{\mathrm{t}} \ldots(2)
$$

Dengan asumsi adanya Breaks, maka ditambahkan variabel eksogen (Z) dalam persamaan (2) dimana variabel eksogen tersebut adalah variabel dummy berdasarkan hasil uji Structural Brekas Bai-Perron.

$$
\left[\begin{array}{c}
\varepsilon_{S B I S} \\
\varepsilon_{P U A S} \\
\varepsilon_{L n I P I} \\
\varepsilon_{L n C P I}
\end{array}\right]=\left[\begin{array}{cccc}
1 & 0 & 0 & 0 \\
\beta 21 & 1 & 0 & 0 \\
\beta 31 & \beta 32 & 1 & 0 \\
\beta 41 & \beta 42 & \beta 43 & 1
\end{array}\right]\left[\begin{array}{c}
\mathrm{e}_{S B I S} \\
\mathrm{e}_{P U A S} \\
\mathrm{e}_{\text {LnIPI }} \\
\mathrm{e}_{\text {LnCPI }}
\end{array}\right] \ldots
$$

\footnotetext{
${ }^{9}$ Lihat Jain-Chandra \& Unsal (2014)

${ }^{10}$ Ibid..
} 
Secara hipotesis, SBIS berdampak negative terhadap return PUAS dan menurunkan output dan inflasi. Transmisi moneter bebas bunga dimulai ketika BI merubah instrumennya. Proses transmisi melalui beberapa langkah: pertama, kebijakan bebas bunga bekerja melalui bonus SBIS untuk mempengaruhi return PUAS sehingga berdampak pada jumlah dana bank, kedua, skenario dilanjutkan pada perubahan return bank. Ketiga, skenario tersebut berdampak pada tingkat deposito, rasio pinjaman konsumsi, dan rasio pinajaman investasi. Terakhir, transmisi dari sektor finansial ke sektor riil bergantung pada efek pendapatan, efek substitusi, dan biaya modal, yang berkahir pada perubahan tingkat output dan inflasi ${ }^{11}$.

\section{HASIL DAN PEMBAHASAN}

\section{Unit root test}

Sebelum melakukan estimasi, prosedur standar yang dilakukan dalam penelitian runtun waktu adalah memeriksa stasioneritas variabel penelitian. Sebagai perbandingan, penelitian menampilkan uji unit root standar Augmented Dickey-Fuller yang kemudian diikuti dengan uji unit root dengan break menggunakan uji Bai-Perron. Tabel 1 menunjukkan hasil uji ADF dimana variabel SBIS dan PUAS stasioner ditingkat I(0) sedangkan variabel LnIPI dan LnCPI stasioner ditingkat I(1).

Table 1. Uji Augmented Dickey-Fuller

\begin{tabular}{|l|l|l|l|}
\hline No & \multirow{2}{*}{ Variabel } & Level & $\mathbf{1}^{\text {st }}$ Difference \\
\cline { 3 - 4 } & & Probability & Probability \\
\hline 1 & SBIS & $0.0029^{* * *}$ & $0.0000^{* * *}$ \\
\hline 2 & PUAS & $0.0088^{* * *}$ & $0.0000^{* * *}$ \\
\hline 3 & LnIPI & 0.7205 & $0.0000^{* * *}$ \\
\hline 4 & LnCPI & 0.3277 & $0.0000^{* * *}$ \\
\hline
\end{tabular}

Note: *** Signifikan pada $1 \%,{ }^{* *}$ signifikan pada $5 \%,{ }^{*}$ signifikan pada $1 \%$. Tingkat signifikansi menunjukkan bahwa variabel stasioner.

Sementara itu, Tabel 2 menampilkan hasil uji unit root dengan Structural Breaks pada model penelitian. Dengan menggunakan model transmisi bebas bunga yang ditunjukkan oleh proksi kebijakan moneter bebas bunga (SBIS), disimpulkan bahwa terdapat pergeseran regime yang ditunjukkan oleh 4 significant structural break dates selama periode penelitian. Breaks yang ditemukan adalah Desember 2014, September 2015, Januari 2017, dan Maret 2018. Pada periode-periode Breaks tersebut, pergeseran perilaku bertepatan pada perbubahan nilai tukar Rupiah terhadap Dollar baik terdepresiasi maupun terapresiasi. Selain itu,

11 Lihat Ascarya (2014) 
perubahan harga secara umum juga ditemukan pada periode Breaks baik inflasi maupun deflasi. Breaks pada 2015 juga bertepatan pada kebijakan devaluasi China tahun 2015 terhadap mata uangnya sehingga berdampak pada kejutan di pasar global ${ }^{12}$.

Tabel 2. Uji Bai-Perron multiple structural breaks

\begin{tabular}{|l|l|l|}
\hline Model & Significant Structural Break dates & Critical value \\
\hline Jalur bebas bunga (SBIS) & $2014: 12$ & 16.19 \\
\hline & $2015: 09$ & 18.11 \\
\hline & $2017: 01$ & 18.93 \\
\hline & $2018: 03$ & 19.64 \\
\hline
\end{tabular}

Note: Tabel 2 menunjukkan significant structural break dates. Uji menggunakan 5 maksimum break, sementara $\sup _{\mathrm{T}}(l+1 \mid I)$ statistics breaks ditunjukkan dalam kurung $(0$. Nilai kritis $\operatorname{supF}_{\mathrm{T}}(l+1 \mid I)$ ditingkat $5 \%$ diperoleh dari Bai-Perron (2003).

\section{Structural VAR}

Hasil estimasi menggunakan SVAR dijelaskan melalui IRF gambar 1 dan gambar 2. IRF gambar 1 menunjukkan pengaruh signifikan SBIS terhadap output ditingkat $5 \%$ sedangkan IRF gambar 2 menunjukkan pengaruh signifikan PUAS terhadap inflasi ditingkat 10\%. Sementara itu, variabel-variabel lain tidak menunjukkan pengaruh yang signifikan.

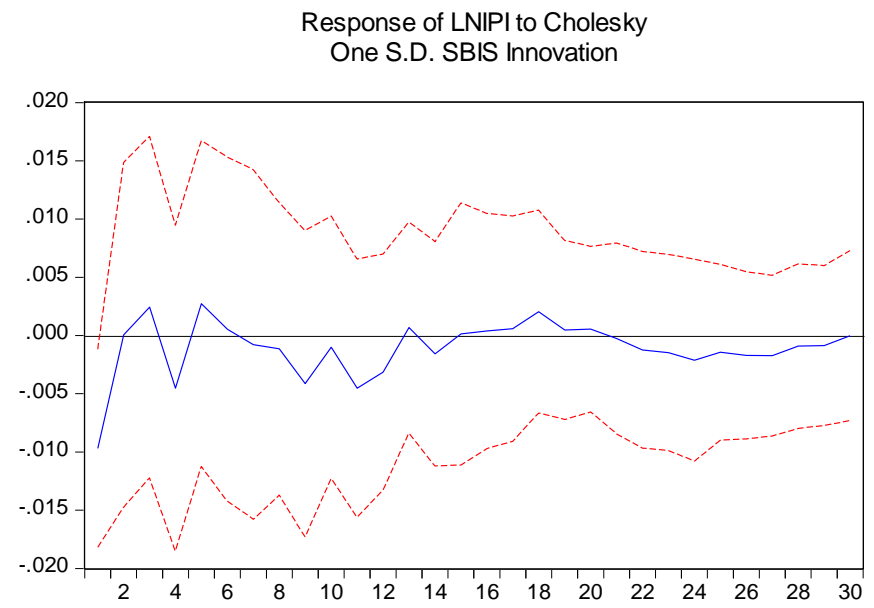

Gambar 1. Impulse Response Function Output terhadap SBIS

Gambar 1 menunjukkan respon Output yang berfluktuatif terhadap shock SBIS. Shock SBIS direspon positif oleh Output hanya pada periode 2, 5, 13 dan 15,

\footnotetext{
${ }^{12}$ Lihat Laporan Perkekonomian Indonesia (https://www.bi.go.id/id/publikasi/laporantahunan/perekonomian/Default.aspx)
} 
sedangkan periode lain menampilkan respon negatif Output terhadap Shock. Hal ini menunjukkan bahwa Output dan SBIS memiliki hubungan yang negatif. Gambar 2 menampilkan respon Inflasi terhadap shock PUAS. Shock PUAS direspon positif oleh Inflasi hanya pada periode 4, sedangkan periode lain direspon negatif oleh Output. Hasil ini menjelaskan bahwa SBIS dapat menurunkan tingkat Output akibat berkurangnya uang beredar sebagai konsekuensi kebijakan SBIS yang menyerap jumlah uang. Sedangkan peningkatan rate PUAS akan berdampak pada kenaikan tingkat imbalan yang dibebankan pada debitur bank sehingga memunculkan efek substitusi yang berdampak negatif dengan tingkat inflasi.

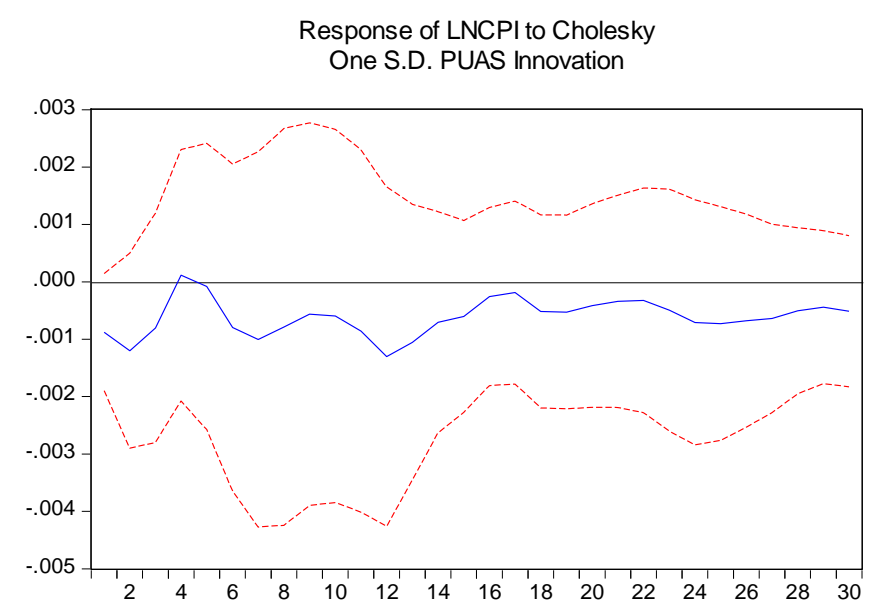

Gambar 2. Impulse Response Function Inflasi terhadap PUAS

\section{KESIMPULAN}

Tujuan penelitian ini adalah untuk menguji keberadaan pergeseran regime yang ditunjukkan dengan adanya Structural Breaks dalam data runtun waktu pada indikator makroekonomi dalam transmisi kebijakan moneter bebas bunga di Indonesia. Hasil penelitian menyimpulkan adanya pergeseran regime yang didasari oleh argumen munculnya 4 structural breaks yang signifikan. Sedangkan SVAR menyimpulkan adanya hubungan negatif antara SBIS dengan tingkat Output dan hubungan yang juga negatif antara rate PUAS dengan tingkat Inflasi. 


\section{DAFTAR PUSTAKA}

Antoshin, S., \& Andrew, B., \& Marcos, S. (2008). Testing for Structural Breaks in Small Samples. IMF working papers.

Ascarya. (2014). Monetary Policy Transmission Mechanism Under Dual Financial System In Indonesia: Interest-Profit Channel. International Journal Of Economics, Management And Accounting 22, No. 1, 1-32

Bai, J., Perron, P. (1998). Estimating and testing linear models with multiple structural changes. Econometrica 66, 47-78.

Bai, J., Perron, P. (2003a). Computation and analysis of multiple structural change models. Journal of Applied Econometrics 18, 1-22.

Bai, J., Perron, P. (2003b). Critical values for multiple structural change tests. Econometrics Journal 6, 72-78.

Greenwald, Bruce Dan Stiglitz, Joseph E. (2003). Toward A New Paradigm In Monetary Economics. United Kingdom: Cambridge University Press

Jain-Chandra, S., \& Unsal, D. F. (2014). The Effectiveness Of Monetary Policy Transmission Under Capital Inflows: Evidence From Asia. Borsa Istanbul Review, 14(2), 96-103.

Lee, C., \& Chang, C. (2005). Structural Breaks, Energy Consumption, And Economic Growth Revisited: Evidence From Taiwan, 27, 857-872. Https://Doi.Org/10.1016/J.Eneco.2005.08.003

Mishkin, F. S. (1995). Symposium On The Monetary Transmission Mechanism. Journal Of Economic Perspectives, 9(4), 3-10.

Phillips Pcb, Perron P. (1988). Testing For A Unit Root In Time Series Regression. Biometrica 75: 335-346

Taylor, John B. (1995). The Monetary Transmission Mechanism: An Empirical Framework. Journal Of Economic Perspectives, Vol. 9, No. 4, Pp 11-26.

Uddin, M. A., \& Halim, A. (2015). Islamic Monetary Policy: Is There An Alternative Of Interest Rate?, (67697). Retrieved From Https://Mpra.Ub.UniMuenchen.De/67697/ 